\title{
Effects of slow frequency electrical stimulation on muscles of dystrophic mice
}

\author{
P LUTHERT, G VRBOVÁ, AND K M WARD \\ From the Department of Anatomy and Embryology, University College of London
}

SUMMARY The hind leg muscles of dystrophic mice (C57 BL dy ${ }^{2 \mathrm{~J}} / \mathrm{dy}^{2 \mathrm{~J}}$ ) were chronically stimulated at $10 \mathrm{~Hz}$ for 30 minutes six times a day. After 14 days of such activity a clinical improvement in the use of the stimulated leg was noticed. The twitch and tetanic tensions developed by the stimulated tibialis anterior and extensor digitorum longus muscles were higher than those developed by the control, unstimulated muscles on the contralateral side. Histochemically visualised activity of the oxidative enzyme succinic dehydrogenase was greater in fibres of the stimulated muscles. The stimulated muscles contained more muscle fibres than unstimulated controls. It is concluded that slow frequency activity has a beneficial effect on muscles of dystrophic mice.

It has been reported that in dystrophic mice, muscle fibres from slow muscles with predominantly oxidative metabolism, are less affected by the disease process than predominantly glycolytic fibres from fast muscles. ${ }^{1-3}$ During early stages of development of mammalian muscles glycolytic pathways are not yet fully differentiated. ${ }^{4}$ It may be that the degeneration of muscles seen in dystrophic mice $^{2}$ gets under way only when muscle fibres develop, and increase the use of their glycolytic pathways.

This possibility is consistent with the observation on mice, that during early stages of development, the dystrophic siblings are indistinguishable from their littermates, and show symptoms of disease only when glycolytic muscle fibres complete normal differentiation, that is at about four to six weeks of age. It is now possible to induce the development of oxidative metabolic pathways in glycolytic muscle fibres by superimposing a slow frequency activity pattern on to the normal activity of fast muscles. ${ }^{56}$ In view of the greater resistance of oxidative muscle fibres to the disease process an attempt is made to study whether a slow frequency activity pattern imposed onto muscles of dystrophic mice would be beneficial. Preliminary results have indeed shown beneficial effects of slow frequency activity on dystrophic muscles. ${ }^{?}$

Address for reprint requests: Dr G Vrbová, Department of Anatomy and Embryology, University College, Gower St London WC1E 6BT.

Accepted 13 March 1980

\section{Methods}

Thirteen Dystrophic mice of the strain C57 BL $2 \mathrm{dy}^{2 \mathrm{~J}} / \mathrm{dy}^{2 \mathrm{~J}}$ were used in these experiments. The weight of the animals ranged from 11 to $23 \mathrm{~g}$. All the animals showed clinical signs of the disease, but the severity of their affliction varied as indicated in tables 1 and 2 . Under ether anaesthesia using sterile precautions Teflon-coated stainless steel wires (diameter of bare wire 0.003 in and coated wire $0.0045 \mathrm{in}$ ) were implanted either side of the lateral popliteal nerve in one hind leg; the other leg serving as a control. The Teflon coating was removed from the ends over a length of $0.5 \mathrm{~mm}$. A fine silk thread was used to attach the wires to the lateral gastrocnemius muscle. The wires were led under the skin and externalised at the neck of the animal, where the ends were attached to two small hooks and sewn to the skin.

The animals were left to recover and stimulated daily via the implanted electrodes, or left unstimulated for control experiments.

At various intervals after the initial operation the animals were anaesthetised with chloralhydrate $(1 \mathrm{ml} /$ $100 \mathrm{~g}$ of body weight of a $3.5 \%$ solution). The tendons of the tibialis anterior (TA) and extensor digitorum longus (EDL) muscles were freed, and attached to fine silk threads. The sciatic nerve was dissected and cut centrally and the medial popliteal nerve was cut distally. Small rigid pins were put through the proximal and distal end of the tibia and the legs were then secured to a rigid table. Contractions were elicited by stimulating the sciatic nerve by supramaximal stimuli. The tendons were attached to strain gauges (Devices $2 \mathrm{oz}$ ) so as to record isometric contractions. These were displayed on an oscilloscope screen and photographed. The body temperature was maintained at $35^{\circ} \mathrm{C}$.

After the recordings were completed the muscles were 
Table 1 Twitch and tetanic tensions and the number of muscle fibres of control and stimulated muscles

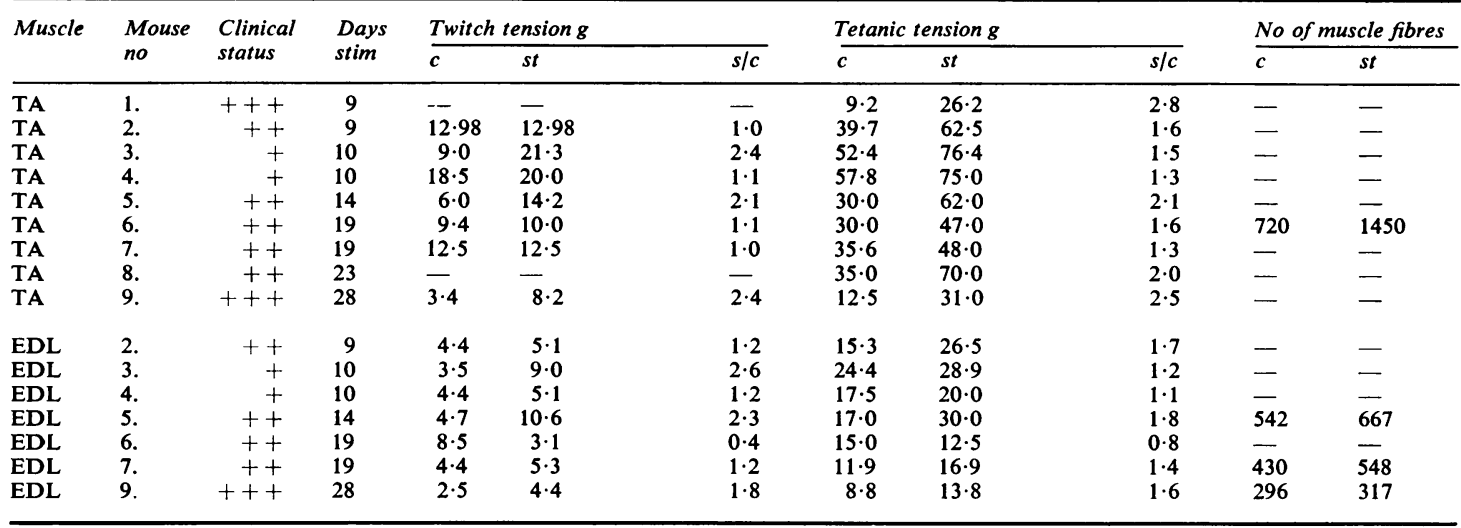

TA $=$ Tibialis anterior

$\mathrm{EDL}=$ Extensor digitorum longus

Clinical status: +++ severely effected

++ less severely effected

+ least severely effected

Table 2 Twitch and tetanic tensions of control and implanted but not stimulated muscles

\begin{tabular}{|c|c|c|c|c|c|c|c|c|c|}
\hline \multirow[t]{2}{*}{ Musclo } & \multirow{2}{*}{$\begin{array}{l}\text { Mouse } \\
\text { no }\end{array}$} & \multirow{2}{*}{$\begin{array}{l}\text { Clinical } \\
\text { status }\end{array}$} & \multirow{2}{*}{$\begin{array}{l}\text { Days } \\
\text { stim }\end{array}$} & \multicolumn{3}{|c|}{ Twitch tension } & \multicolumn{3}{|c|}{ Tetanic tension } \\
\hline & & & & $\bar{c}$ & $o p$ & $\overline{o p / c}$ & $\bar{c}$ & $o p$ & $\overline{o p / c}$ \\
\hline $\begin{array}{l}\text { TA } \\
\text { TA } \\
\text { TA } \\
\text { TA }\end{array}$ & $\begin{array}{l}1 c \\
2 c \\
3 c \\
4 c\end{array}$ & $\begin{array}{r}++ \\
++ \\
++ \\
+++\end{array}$ & $\begin{array}{l}15 \\
20 \\
22 \\
37\end{array}$ & $\begin{array}{r}16 \cdot 8 \\
18 \cdot 3 \\
14 \cdot 4 \\
8 \cdot 8\end{array}$ & $\begin{array}{r}17.4 \\
10.0 \\
11.1 \\
5.6\end{array}$ & $\begin{array}{l}1.0 \\
0.5 \\
0.8 \\
0.6\end{array}$ & $\begin{array}{l}81 \cdot 3 \\
59 \cdot 4 \\
54 \cdot 6 \\
30 \cdot 0\end{array}$ & $\begin{array}{l}62 \cdot 5 \\
37 \cdot 5 \\
50 \cdot 1 \\
25 \cdot 0\end{array}$ & $\begin{array}{l}0.8 \\
0.6 \\
0.9 \\
0.8\end{array}$ \\
\hline $\begin{array}{l}\text { EDL } \\
\text { EDL } \\
\text { EDL } \\
\text { EDL }\end{array}$ & $\begin{array}{l}1 c \\
2 c \\
3 c \\
4 c\end{array}$ & $\begin{array}{r}+ \\
++ \\
++ \\
+++\end{array}$ & $\begin{array}{l}15 \\
20 \\
22 \\
37\end{array}$ & $\begin{array}{r}4 \cdot 6 \\
10 \cdot 0 \\
7 \cdot 8 \\
5 \cdot 0\end{array}$ & $\begin{array}{l}3 \cdot 7 \\
6 \cdot 3 \\
4 \cdot 4 \\
3 \cdot 8\end{array}$ & $\begin{array}{l}0.8 \\
0.6 \\
0.6 \\
0.8\end{array}$ & $\begin{array}{l}25 \cdot 2 \\
14 \cdot 8 \\
21 \cdot 1 \\
16 \cdot 3\end{array}$ & $\begin{array}{l}14 \cdot 8 \\
19 \cdot 3 \\
20 \cdot 0 \\
15 \cdot 6\end{array}$ & $\begin{array}{l}0.6 \\
1.3 \\
0.94 \\
0.95\end{array}$ \\
\hline
\end{tabular}

TA = Tibialis anterior

$\mathrm{EDL}=$ Extensor digitorum longus

c = control

st $=$ stimulated

Clinical status: +++ severely effected

c $=$ control

++ less severely effected

+ least severely effected

excised, weighed and frozen in isopenthane cooled in liquid nitrogen. The experimental and control muscles from each animal were mounted on either side of a pin and aligned with care so that a similar area from the middle of each muscle was examined. $10-15 \mu \mathrm{m}$ crosssections of both muscles were cut simultaneously. Both experimental and control muscles were then processed together. The enzyme succinic dehydrogenase was visualised using the method of Nachlas, Tsou, De Souza, Cheng and Seligman. ${ }^{8}$ Some sections were also stained with haematoxylin-eosin, or haematoxylin van Gieson. Enlarged photographs were prepared and from these the number of muscle fibres counted, and fibre diameters measured.

\section{Results}

(1) Effects of electrical stimulation on the physiological properties of tibialis anterior and extensor digitorum longus

Nine dystrophic animals were used. The mice were between three and five months old and severely effected by the disease. They dragged their hind legs and could not dorsiflex their ankle joints. After the electrodes were implanted on one side the mice were connected to a stimulator and muscles supplied by the lateral popliteal nerve were activated continuously at 8 to $10 \mathrm{~Hz}$ so that the contractions of the tibialis anterior could be felt. The animals were carefully observed and it was noticed that after 45 to $60 \mathrm{~min}$ of such stimulation the muscles fatigued and contractions could no longer be observed. If the muscles were stimulated for one hour or more the muscles recovered only after 12 to 24 hours of rest. After trying different intervals of stimulation it was found that stimulating the muscles for $30 \mathrm{~min}$ at 8 to $10 \mathrm{~Hz}$ and leaving $30 \mathrm{~min}$ recovery did not cause fatigue. This type of stimulation and rest was repeated six times a day so that the total time of stimulation was three hours per day. 
The animals' ability to walk and move their legs was examined each morning before they were connected to the stimulator. In five out of nine animals studied, it was noticed that after the tenth day of stimulation the mice were able to dorsiflex their ankle and use the stimulated leg for walking, while they dragged the other leg behind them. Naive observers could easily point out which leg had been stimulated.

In the final experiment the animals were anaesthetised and their TA and EDL muscles set up for tension recording. Single twitches as well as tetanic contractions (at 20 to $100 \mathrm{~Hz}$ ) were elicited and recorded. The muscles developed maximum tension at 60 to $80 \mathrm{~Hz}$ and the values used in the figures and tables are those obtained by stimulation at $80 \mathrm{~Hz}$. Fig 1 shows records of single twitches and fig 2 of tetanic contractions obtained from TA muscles from a dystrophic mouse 14 days after chronic stimulation. It is apparent that the twitch and tetanic tensions developed by the stimulated muscle are greater than those developed by the control muscle.

Table 1 and fig 3 summarise the results from all experiments and compare the tensions developed by the stimulated and unstimulated dystrophic muscles of individual animals. In each case the stimulated TA developed higher tensions than the control muscle. Results obtained on EDL were similar, but the improvement in general was less and in one animal the stimulated EDL developed slightly less tension than its unstimulated control. Fig 3 and table 1 show that the percentage improvement
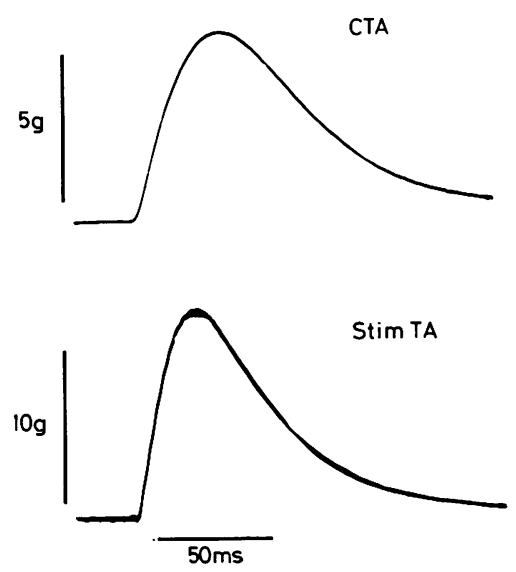

Fig 1 Mouse 3. Records of isometric single twitches elicited by stimulating the lateral popliteal nerve of the control and 14 days stimulated $T A$ muscles are shown.

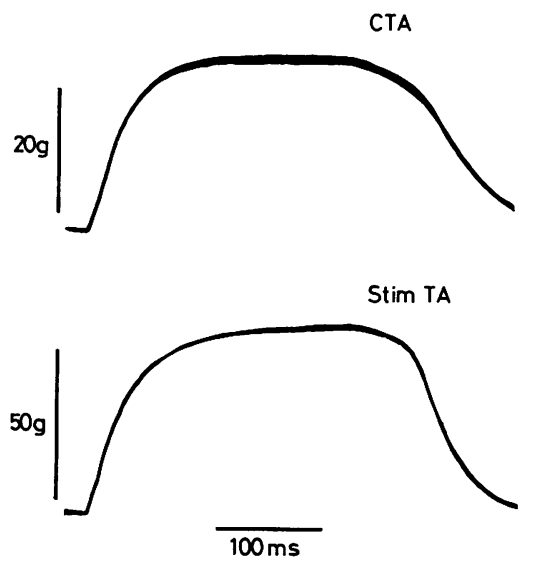

Fig 2 Mouse 3. Records of tetanic contractions $(80 \mathrm{~Hz})$ developed by control and 14 days stimulated $T A$ muscles.

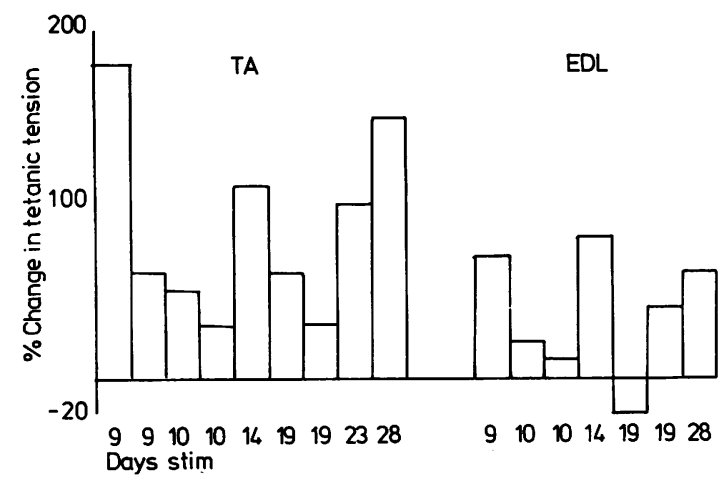

Fig 3 Chunges of tetanic tension developed by stimulated muscles expressed as a percentage increase or decrease. The tension developed by the contralateral muscles is taken as $100 \%$.

bears no relationship to the duration of stimulation. This lack of correlation could be due to the fact that the mice used in these experiments were not a homogeneous group. Their age ranged from three to five months and the severity of their affliction was variable (tables 1 and 2). This is also apparent from the great range of tensions developed by the control, unstimulated muscles of individual animals (table 1).

The time course of contraction was not significantly effected by the stimulation. Time to peak tension of the stimulated TA muscles was $21 \pm 2 \cdot 4 \mathrm{~ms}$ ( 7 muscles) that of the control TA muscles $25 \pm$ $3.6 \mathrm{~ms}$ (7 muscles), time to peak of stimulated EDL muscle was $21 \cdot 1 \pm 2 \cdot 9$ (6 muscles) and that of the 
control EDL $24 \pm 3.9 \mathrm{~ms}$ (6 muscles). Neither was there any difference in the weight of stimulated and control muscles. This is not surprising in view of large amounts of connective tissue and degenerating muscle fibres present in diseased muscle.

In four control experiments electrodes were implanted into dystrophic mice as in the previous series, but the muscles were not stimulated. No functional improvement was noticed in these animals, and the tensions developed by the TA and EDL muscles on the side of implantation of electrodes was usually less than that developed by the muscles of the contralateral side (table 2). Thus it appears that implantation of electrodes alone was disadvantageous.

In normal rabbits or rats the type of activity used in the present experiments does not lead to an increase of tension developed by the stimulated muscles. To test whether this also applies to mice, electrodes were implanted in one littermate of the dystrophic mice with no symptoms of the disease and TA and EDL muscles were stimulated in one leg. After two weeks of stimulation with a similar activity pattern as that used for the dystrophic mice the maximal tetanic tension developed by the stimulated TA was $68 \mathrm{~g}$ and that developed by the stimulated EDL $16 \mathrm{~g}$. The control TA developed $72 \mathrm{~g}$ and EDL $19 \mathrm{~g}$. Thus, as in rabbits and rats, in normal mice this type of stimulation does not appear to cause the muscles to develop higher tensions.

\section{(2) Light microscopy of control and stimulated muscles}

Normal TA or EDL muscles of mice, when stained for the oxidative enzyme SDH show the typical mosiac type appearance with different fibres showing various degrees of enzyme activity (fig 4a). The same muscles of dystrophic animals stain more uniformly and have only very few lightly stained fibres (fig 4b). Muscles of dystrophic mice that had been stimulated for two to four weeks contain fibres that also stain uniformly but more intensely for SDH than the control unstimulated muscles.
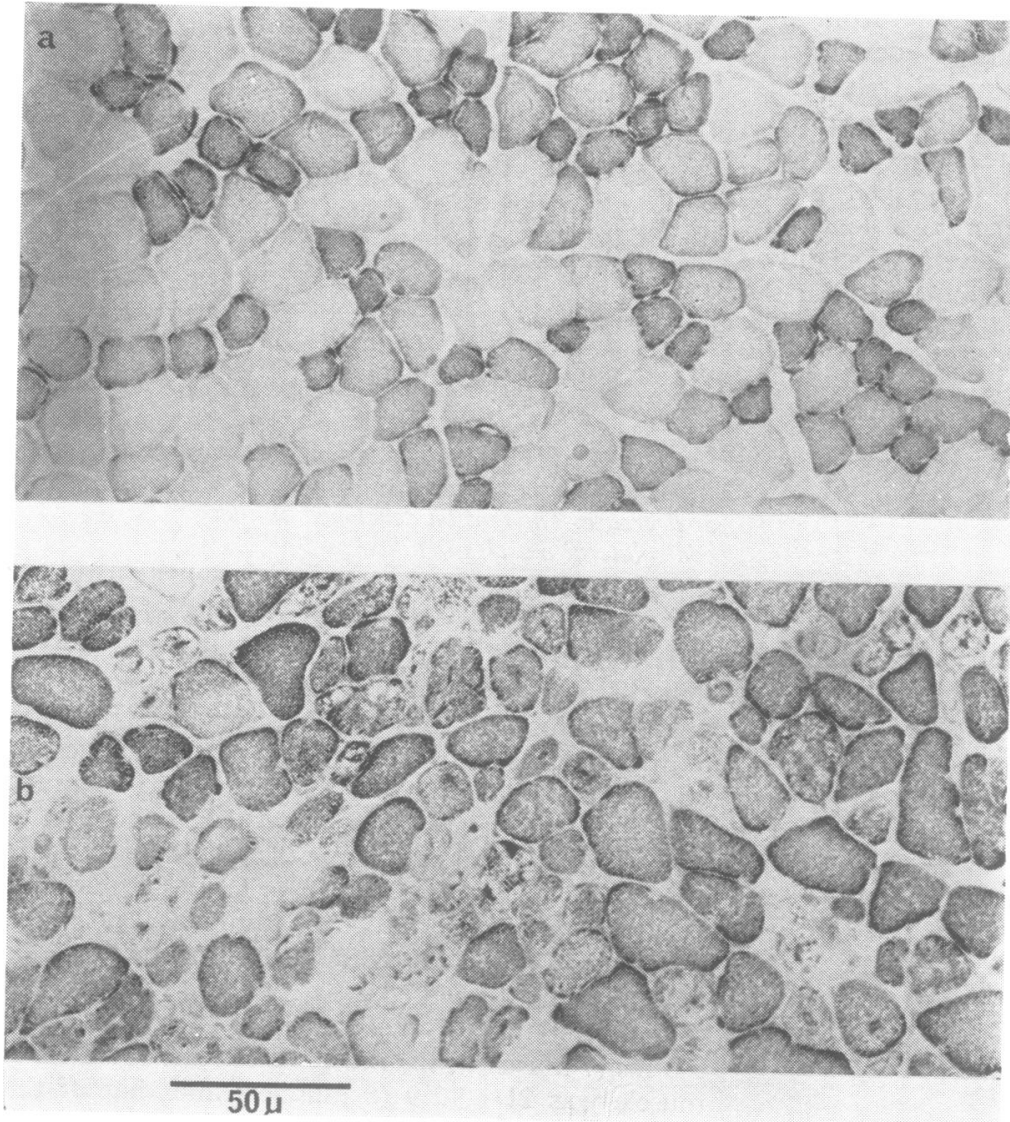

Fig 4 Succinic dehydrogenase $(S D H)$ in a control $(a)$ and dystrophic (b) TA muscle. The bar represents $50 \mu \mathrm{m}$. 

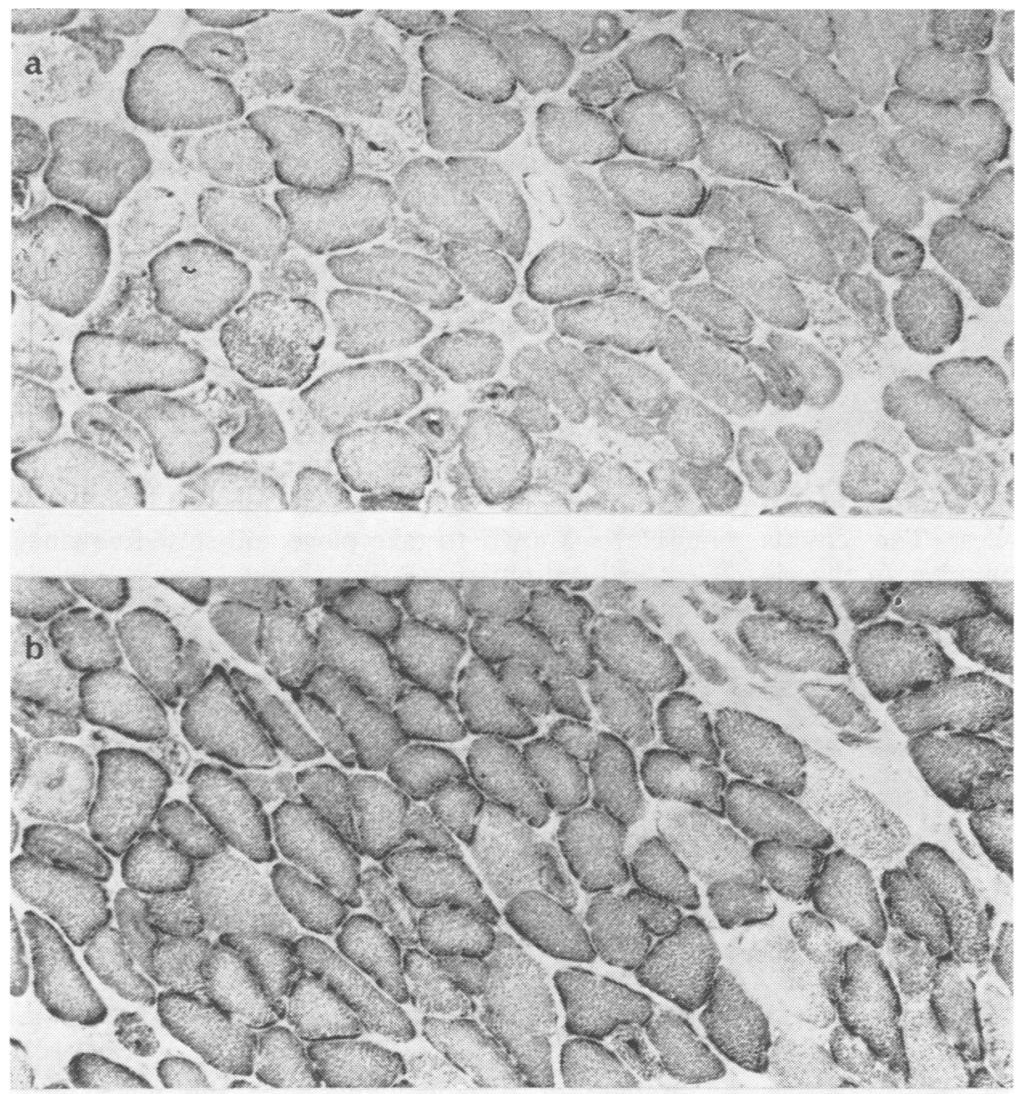

Fig 5 Mouse No 7 SDH activity in a dystrophic (a) and dystrophic stimulated (b) TA muscle. The bar represents $50 \mu \mathrm{m}$.
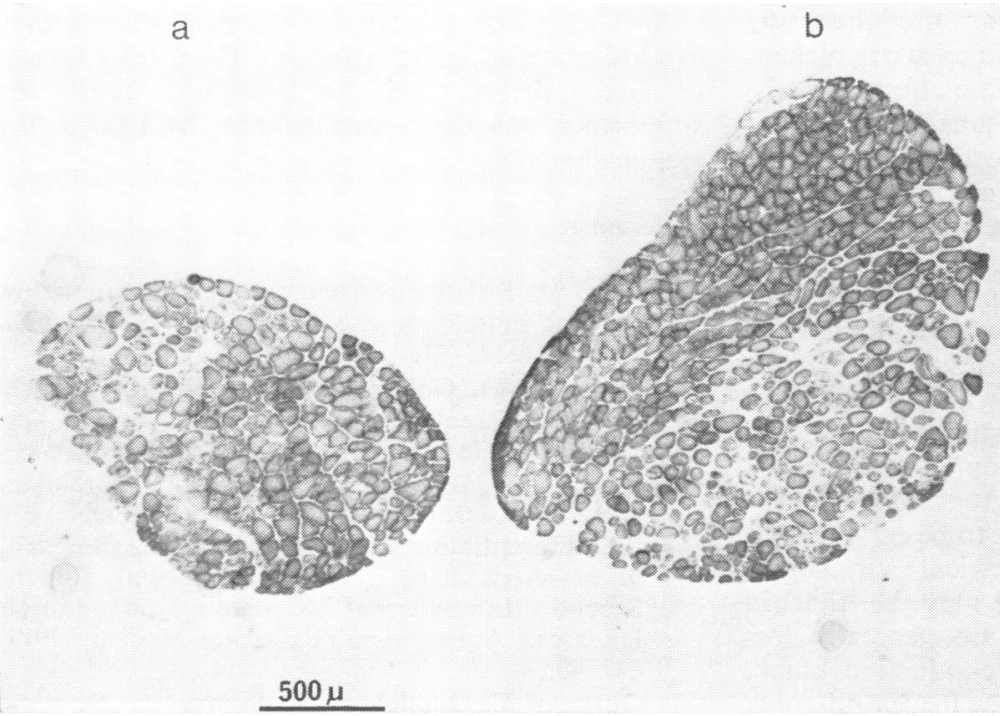

Fig 6 Mouse No 7 SDH activity in the control (a) and stimulated (b) EDL. The bar represents $500 \mu$. 
Fig 5 shows an example from such an experiment and compares the control TA (fig 5a) to the stimulated TA (fig 5b) from the same animal after 19 days of stimulation.

A low power photomicrograph of the control (fig 6a) and stimulated (fig 6b) EDL muscles from the same animal show the overall change induced by stimulation for 19 days. This figure also shows that the stimulated muscle contains more muscle fibres than the unstimulated control.

Muscles stained with haematoxylin-eosin, or haematoxylin van Gieson also indicated that many more muscle fibres were present in the stimulated muscle than in the control unstimulated one. The number of muscle fibres was counted in control and stimulated EDL and TA muscles. The counts revealed that there was a higher number of muscle fibres in the stimulated than in the control muscle (table 1). Fibre diameter was also measured, but no consistent difference between control and stimulated muscles was revealed.

\section{Discussion}

There are several indications that muscle fibres of dystrophic mice have the ability to develop and attain a certain degree of maturity, but subsequently degenerate. ${ }^{910}$ It is possible that it is during differentiation that the muscle fibres acquire a particular characteristic that makes them susceptible to the disease process.

During early stages of muscle development neither oxidative nor glycolytic metabolic pathways are highly developed in individual muscle fibres. ${ }^{411}$ With further development muscle fibres differentiate into predominantly oxidative or predominantly glycolytic fibres, and in dystrophic mice or chickens the glycolytic fibres seem to become affected by the disease and degenerate. ${ }^{3}{ }^{11}$ The results of the present study show that slow frequency clectrical stimulation which favours the development of oxidative pathways in muscle fibres ${ }^{5}$ has a beneficial effect on muscles of dystrophic mice. The dystrophic muscles, when stimulated for even relatively short periods of time, developed more tension than the unstimulated controls and more muscle fibres survived in such a stimulated muscle. The relative small increase in weight of the stimulated muscles may be due to the fact that in dystrophic unstimulated muscles connective tissue and fat replace the degenerating muscle fibres. It is difficult to be certain as to the mechanism by which electrical stimulation effects the diseased muscle. It may be that in dystrophic mice muscle fibres are generally less active possibly as a result of a conduction block, since it is known that nerve fibres in ventral roots of the lumbosacral region of the cord show unmyelinated fibres. ${ }^{13}$ Stimulation of the peripheral nerve below this lesion may therefore increase the amount of activity and in this way lead to an improvement of the condition of the muscle. We do not consider this a likely mechanism, for inactivity reduces the number of fibres with high activities of oxidative enzymes, while effecting fibres with high glycolytic capacity less; this is not what is seen in the muscles of dystrophic mice.

The finding that the number of fibres is greater in stimulated than in control muscles indicates that stimulation may effect newly regenerated muscle fibres and prevent their subsequent degeneration. Formation of "new" muscle fibres in diseased muscle is known to take place and slow frequency electrical stimulation in these "new" muscle fibres may increase their oxidative capacity and reduce the development of their glycolytic pathways. This possibility is supported by the finding that in the stimulated muscles the activity of the oxidative enzyme 5DH was higher in all fibres. It could be that these muscle fibres become more resistant to the disease process, and have a better chance of survival.

Whether or not this suggestion is correct the results of the present investigation could be important when considering treatment of those forms of human muscular dystrophies where there is a preferential involvement of glycolytic muscle fibres such as is the case in Duchenne dystrophy. ${ }^{14} 15$ Moreover, a further analysis of the mechanism underlying the beneficial effects of slow frequency stimulation could elucidate the pathogenesis of muscular dystrophies.

We are grateful to the Muscular Dystrophy Group of Great Britain and the Wellcome Trust, for supporting this work, and to Mrs M Lowrie for technical advice.

\section{References}

1 Brust M. Relative resistance to dystrophy of slow skeletal muscle of the mouse. Amer J Physiol 1966; 210:445-51.

2 Rowe RWD, Goldspink G. Muscle fibre growth in five different muscles in both sexes of mice. II. Dystrophic mice. J Anat 1969; 104:531-8.

3 Cosmos E, Butler J, Milhorat A. Hereditary muscular dystrophy: a possible myogenic defect in the differentiation of muscle. In: Basic Research in Myology. Part I of the Proceedings of the Second International Congress on Muscle Diseases. Amsterdam: Excerpta Medica, 1971: 632-40.

4 Gutman E, Melichna J, Syrovy I. Develop- 
mental changes in contraction time, myosin properties and fibre patterns of fast and slow skeletal muscles. Physiol Bohemoslov 1974; 23: 19-27.

5 Pette D, Smith ME, Staudte HW, Vrbová G. Effect of long-term electrical stimulation on some contractile and metabolic characteristics of fast rabbit muscles. Pflugers Arch 1973; 338:257-72.

6 Brown MD, Cotter MA, Hudlická O, Vrbová G. The effect of different patterns of muscle activity on capillary density, mechanical properties, and structure of slow and fast rabbit muscles. Pflügers Arch 1976; 361:241-50.

7 Luthbert P, Vrbová G, Ward KM. Functional improvement of sekeletal muscles of dystrophic mice following electrical stimulation. J Physiol 1979; 291:31p.

8 Nachlas M, Tsou MK, De Souza E, Cheng C, Seligman AM. Cytochemical demonstration of succinic dehydrogenase by the use of a new p-nitrophenyl substituted ditetrazole. J Histochem. Cytochem 1957; 5:420-36.

9 Montgomery A, Swenarchuk L. Dystrophic mice show age related muscle fibre and myelinated axon losses. Nature 1977; 267:167-9.

10 Burch TG, Law PK. Normal development of muscle fibres and motor endplates in dystrophic mice. Exp Neurol 1978; 58:570-4.

11 Gordon T, Perry R, Srihari T, Vrbová G. Differentiation of slow and fast muscles in chickens. Cell and Tissue Res 1977; 180:211-22.

12 Mazliah J, Cosmos E, Butler J. Physiological and histochemical analysis of the early transformation of PLD fibres by the ALD nerve in normal and dystrophic birds. Abst. IVth Intern. Congress of Neuromusc. Diseases, Montreal, 1978: 272.

13 Bradley WG, Jenkinson M. Neural abnormalities in the dystrophic mouse. J Neurol Sci 1975; 25: 249-55.

14 Buchthal F, Kamieniecka Z, Schmalbruch H. Fibre types in normal and diseased human muscles and their physiological correlates. In: Milhorat, ed. Exploratory concepts in Muscular Dystrophy. Amsterdam: Excerpta Medica, 1974: 526-52.

15 Johnson MA, Kohen-Kucukyalcin Dora. Pattern of abnormal histochemical fibre type differentiation in human muscle biopsies. J Neurol $\mathbf{S} c i$ 1978; 37:159-78. 